\title{
Postprandial insulin responses to a low- and high-glycaemic index mixed meal
}

\author{
M. Gibbs, D. Harrington, S. Starkey and S. Hampton \\ Faculty of Health and Medical Sciences, University of Surrey, Guildford, Surrey GU2 7XH, UK
}

Postprandial hormone and metabolic responses have been shown to alter depending on the time of the day the meal is consumed ${ }^{(1,2)}$. This study investigates diurnal change in postprandial insulin responses after high-glycaemic (HGI) and low-glycaemic (LGI) macronutrientmatched meals. It was hypothesised that the insulin responses of HGI and LGI meals would be greater in the evening compared to the morning, as previously reported for the postprandial glucose responses ${ }^{(3)}$.

In a randomised control, single-blind crossover study, 10 healthy subjects $(9 \mathrm{~F}, 1 \mathrm{M})$ mean age 25.5 years $( \pm 8.8 \mathrm{SD})$ with BMI of $21.9 \mathrm{~kg} / \mathrm{m}^{2}(1.7 \mathrm{SD})$, were given a HGI, LGI meal in the morning or the evening on four separate occasions. However, due to small sample volumes, complete sets of insulin results were only achieved in six subjects. The meal composition was matched for energy, carbohydrate, fat and protein. Subjects were fasted (minimum $8 \mathrm{~h}$ ) following a controlled low-GI pre-meal, prior to each leg of the study. Blood samples were taken using a finger-prick method, at baseline (0), 15, 30, 45, 60, 90 and 120 min postprandially. Plasma insulin levels were determined by chemiluminescent ELISA (Invitron Ltd, Monmouth, UK). Comparisons between meals and diurnal comparisons were made by repeated measures ANOVA and significance was accepted at $P=0.05$.

No significant difference was observed between fasting levels on all four occasions. Peak insulin response was delayed after both evening HGI and LGI meals (42.50 ( \pm 9.0) HGIam, 72.5 ( \pm 13.6$)$ HGIpm $P=0.028,42.5( \pm 2.7)$ LGIam, $70( \pm 22.50)$ LGIpm $P=0.03$ [mean (SEM)], min). The area under the insulin response curves was not significantly different after all four meals: 1159 (654) HGIam $v$. 1236 (348) HGIpm, 1356 (410) LGI am v. 1077 (616) LGIpm, pmol/l·min).

Although we had previously reported a diurnal variation in glycaemic postprandial responses following consumption of LGI and HGI meals in the morning $v$. the evening, no significant variation in postprandial insulin response was observed. This could be due, in part, to only six subject's results being reported and there appeared to be greater variation of insulin responses between individuals and therefore more sample numbers are required.

1. Hampton SM, Morgan LM, Lawrence N et al. (1996) Post prandial hormone and metabolic responses in simulated shift work. $J$ Endocrinol 151, 259-267.

2. Ribeiro D, Hampton SM, Morgan LM et al. (1998) Altered postprandial hormone and metabolic responses in a simulated shift work environment. $J$ Endocrinol 158, 305-310.

3. Gibbs M, Harrington D \& Hampton S (2009) Diurnal variation in glycaemic response to a low and high glycaemic index mixed meal. Proc Nutr Soc Abstract 